\title{
Hospital Administration Management Technology Adoption; A Theoretical Test of Technology Acceptance Model and Theory of Planned Behavior on HAMT Adoption
}

\author{
Ampadu Seth $^{1, *}$, Azamela John Coffie ${ }^{2}$, Amoako Richard ${ }^{1}$, Sarfo Adu-Yeboah Stephen ${ }^{3}$ \\ ${ }^{1}$ Hefei University of Technology \\ ${ }^{2}$ University of Electronic Science and Technology of China \\ ${ }^{3}$ Kwame Nkrumah University of Science and Technology \\ *Corresponding author: sethKampadu@yahoo.com
}

Received December 11, 2018; Revised January 12, 2019; Accepted February 04, 2019

\begin{abstract}
This paper focused on broadening users and HAMT technology elite knowledge on the adoption of Hospital Administration Management System Technology base on the amalgamation of Theory of Planned Behavior and Technology Acceptance Model. In regards to this, 236 questionnaires were distributed to health professionals out of which 200 were recouped. The 200 Health Professionals were from different hospitals and clinics for this paper, the makeup of the population sample consist of Nurses, Doctors, and Administrative staff as they form the majority users of HAMT. Every institution needs reliable information or data to operate successfully, it is, therefore, worthwhile to say that information or data on hand has a significant influence on the outcome of treatment of patients. The results of the study fascinatingly demonstrate the significant factors of HAMT adoption and the impact of each delineated element. The outcomes established that the majority of health workers will adopt HAMT base on their Perceived Usefulness, Perceived Ease of Use, Attitude, Subjective Norms and Subjective.
\end{abstract}

Keywords: HAMT, TAM, TPB, health professionals

Cite This Article: Ampadu Seth, Azamela John Coffie, Amoako Richard, and Sarfo Adu-Yeboah Stephen, "Hospital Administration Management Technology Adoption; A theoretical Test of Technology Acceptance Model and Theory of Planned Behavior on HAMT Adoption." American Journal of Public Health Research, vol. 7, no. 1 (2019): 21-26. doi: 10.12691/ajphr-7-1-4.

\section{Introduction}

As the world tries to embrace technology as part of our daily life, every aspect of human life keeps evolving in this direction, almost every organization; institutional settings are doing everything in their power to enhance their service delivery system and to also speed up operations. The health sector has not been left out in this technology proliferation [1]. It seems there is no limit on IT capabilities. Health technology has the ability to enhance life quality, diagnose and provide alternative treatment, keep records of patients health history, beef up health delivery system and also ensure health care cost-effectiveness [1] In a unique working environment, institutions try to find innovative strategies to enhance information sharing [2] such is the brain behind the introduction of Health Administration Management Technology (HAMT). Innovative health care administration and management prolong to be a great influence in the search for quality health care delivery coupled with cost-benefit, this is because such innovation uplift organizational competitiveness and productivity level [1,3] Innovative Management, Service delivery, and creative innovation is important to any establishment as it could be the light for spawning returns, maintaining competition and automatically speeding operational process [1]. HAMT makes it possible for staff and another related department in the hospital access patients' record on a real-time as compared to a traditional system where paper or patient ledger has to be rolled from one department to the other [4].

The adoption and use of Hospital Administration Management System Technology (HAMT) has a potential to decrease patients stay time, reduce cost, save office space, enhance chance in operation and facilitate information dissemination [5]. Hospitals as an entity for delivering health care are tasked to offer patients cure or treatment through health expertise with the requisite technology which would be able to provide fast and adequate information of patients in other to give them the best service [6]. Being innovative does not only speed up the delivery process, it also enhances the competitive nature of an establishment [7]. 


\section{Statement of Problem}

HAMT as an Innovative Healthcare management tool is in the early stage as few Hospitals in Ghana have adopted it and moreover, it's new in the health sector, it is therefore necessary to understand users' acceptance of Hospital Administration Management System Technology as an add on to the current search for a suitable Innovative healthcare Technology.

Adoption of HAMT varies when compared to other countries example is the survey by the AHA (American Hospital Association) concluded that 1.5 percent of Hospital staff have an understanding of HAMT, while another research estimated that 7.6 percent have a basic understanding of the system $[8,9]$.

\subsection{Research Questions}

1. What are the factors that influence the adoption of HAMT?

2. Do Attitude, Usefulness, Ease of Use affect the adoption of HAMT adoption?

3. Can Social Behavior and Subjective Norms impact on HAMT adoption?

\subsubsection{Research Hypothesis}

H1: there is a significant correlation between Attitude and HAMT adoption

H2: Perceived Ease of Use significantly affect HAMT adoption.

H3: Perceived Usefulness is inversely related to HAMT adoption.

H4: there is exist a significant relationship between social Behaviour Control and HAMT adoption

H5: The is a significant relationship between Subjective Norms and HAMT adoption

\section{Literature Review}

Researchers who are keen and passionate about health delivery and administration over the years are always trying to find alternatives to make the health sector more vibrant and Innovative [10]. Researcher such as West stipulated that innovation, in this regard HAMT, should be seen as innovation, amalgamated with the Hospital or clinic modus operandi, scheme, processes as a pertinent component adopted for the inclusive benefit of the hospital, patients and other concern stakeholders, towards a collective objective [11].

\subsection{Technology Acceptance Model}

This paper provides the foundation or starting point for a supplementary filter of theories by amalgamating of variables of TAM (Technology Acceptance Model) and TPB (Theory of Planned Behavior) to ascertain HAMT adoption in Ghanaian Health Institutions. TAM and TPB have been a forefront theory for ascertaining influencer level of adopting technology and again makes it possible to understand users' intention to accept certain technology $[12,13]$. Despite it general acceptance both theories have not been able to establish a concrete or superior forecast of user behavior towards adoption [14,15], this outcome was also stressed by Taylor and Todd [16] This conclusion may be as a result of the type of technology, type of influencers, users intention. Both theories were deduced from TRA which was pioneered by Ajzen and Fischbein [17]. TAM is seen as a commanding theoretical model proposed to predict or forecast the acceptability Variables of Technology, the causative items that will influence an individual to adopt certain technology $[18,19,20]$ this takes into consideration the willingness of a user to accept and adopt such technology. Perceived Usefulness and Perceived Ease of Use of such technology forms the fundamental of TAM [18], TAM was upgraded to TAM to handle other predictive variables that were omitted from TAM1 [21], Although TAM is widely accepted and adopted by researchers, others also condemn and disregard it for not taken into accounts, other cognitive practice to end user behavioral choices [22] despite this limitation TAM is widely used model when it comes to prediction of acceptance of technology [23].

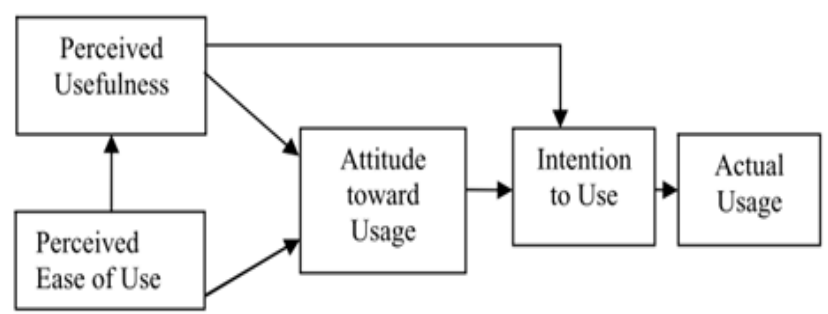

Figure 1. TAM 1 Ajzen and Fischbein [17]

The genesis of Technology Acceptance model began with TRA thus TRA gave birth to models such as TAM and TPB. David argue that Perceived Ease of Use of Technology and Perceived usefulness are the most significant conviction for adopting certain use of technology [24] The level of belief that utilizing certain technology will augment a person's job relates to Perceived usefulness while Perceived ease of use looks at the degree of easily understanding or the effortless demand from users by the technology adopted [25]. The Variables of TAM was later extended by other researchers to cater for development and changes in adoption $[16,26,27]$ while others pioneered other external dynamic such as personal features and demographic attribute to the two key principle construct [28].

\subsection{The theory of Planned Behavior (TPB)}

The theory of planned behavior is used to guess a person's behavior in a mandatory context, as compared to TRA, TPB has a perceived behavior construct in addition to the other variables already captured in TAM [29] Subjective variable has been labeled as the feeble element among the TPB variable constructs $[29,30]$ other researches carried out also seconded the fact that subjective norm correlate negatively with intention to execute a particular behavior [31]. 


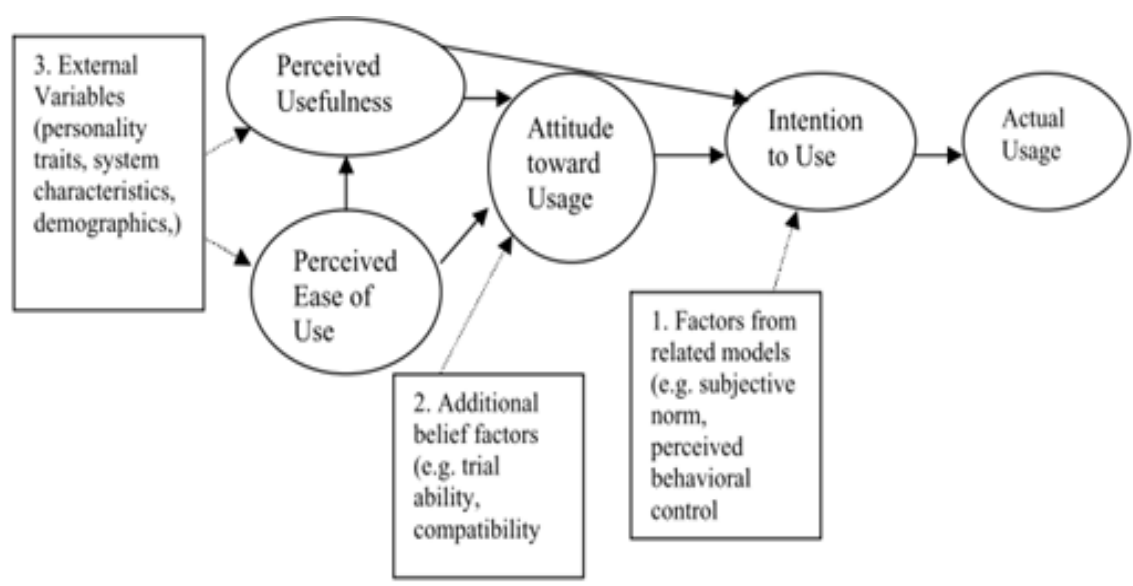

The Extensions to TAM (adapted from Wixom and Todd, 2005)

Figure 2. TAM2 Wixom and Todd (2005)

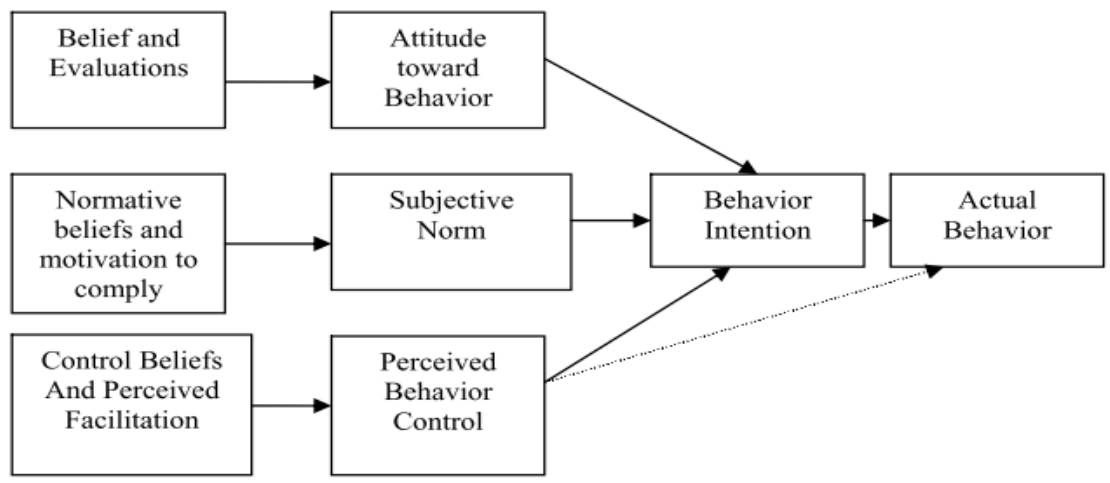

Figure 3. Theory of Planned Behavior (TPB)

The theory of planned behavior was adopted from the Theory of Reasoned Action, it inculcated perceived behavior control as an extra predictor of human action or behavior [32]. The purpose of the theory of planned behavior

\section{Methodology and Data Analysis}

\subsection{Participants and Study Design}

This study was executed with research ethical principles in mind and in accordance with academic research code. Participants were from some selected Public and Government Hospitals around the ten regions of the Republic of Ghana. Questionnaire was administered, participant were made aware of the purpose of the study and its benefits to the world and academic settings. The questionnaire captured all the variables or construct of Technology Acceptance Model and Theory of Planned Behavior thus subjective norm, attitude, Behavior control, Perceived Usefulness, Perceived ease of use. The questionnaires were distributed to random hospital staffs who are directly engaged in Hospital activities. 200 questionnaires were distributed and all of them were filled and returned. The 200 participants consist of 96 males (48\%) and 104 females (52\%), in terms of Job title distribution 93(46.5\%) were nurses, Doctors 19 (9.5\%), Pharmacists 11 (5.5\%), Management and Administration staffs 61(30.5\%) and Lab 16(8\%). Gender, age, and Job has a skewness of $-0.81,1.12$ and 0.329 and a kurtosis of $-2.01,1.05$ and -1.60 , these figures are within the threshold of 3 to -3 .

\subsection{Variable Items and Tools}

The questionnaires were designed to suit the variable construct of Technology Acceptance Model and Theory of Planned Behavior. It initially contains 16 itemized questions on a Likert scale of five, ranging from strongly disagree to strongly agree. The questionnaire weighs up a combined five variables of TAM and TPB thus attitude, Perceived Usefulness, Perceived Ease of Use, Behavior control, and Subjective Norms.

\subsection{Reliability Test}

In order to ascertain the degree of reliability of data collected, an initial test was carried out to estimate the level of reliability of data collected. The result of the test could be seen below:

Table 1. Reliability test

\begin{tabular}{lcccc}
\hline Variables & $\begin{array}{c}\text { No. of } \\
\text { Variable } \\
\text { items }\end{array}$ & $\begin{array}{c}\text { Cronbach } \\
\text { Alpha }\end{array}$ & $\begin{array}{c}\text { Revised No. } \\
\text { of Variable } \\
\text { Items }\end{array}$ & $\begin{array}{c}\text { Revised } \\
\text { Cronbach } \\
\text { Alpha }\end{array}$ \\
\hline Attitude & 4 & 0.27 & 3 & 0.69 \\
Perceived EOU & 3 & 0.86 & - & - \\
Perceived UFN & 3 & 0.65 & - & - \\
Be Have C & 3 & 0.89 & - & - \\
Subjectv N & 3 & 0.78 & - & - \\
\hline
\end{tabular}


The initial 4 items for Attitude gave a Cronbach alpha of 0.27 , as a result, it was revised and one item was deleted, hence given a revised Cronbach alpha of 0.69 . Perceived Ease of Use (PerceivedEOU) gave a Cronbach alpha of 0.86, Perceived Usefulness (PerceivedUFN) gave a Cronbach alpha of 0.65, while Behavior control (BeHaveC) and Subjective items gave a Cronbach alpha of 0.89 and 0.78 respectively. These results indicate that data collected is reliable as it falls within the Cronbach alpha of $0.6>$ or more.

\subsubsection{Correlation Analysis}

A correlation test analysis was carried out to establish the relationship among the variable construct used for this research. The results of the relationship stated below:

Table 2. Correlation Analysis

Correlations

\begin{tabular}{|c|c|c|c|c|c|c|}
\hline \multicolumn{7}{|c|}{ to } \\
\hline & 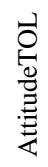 & 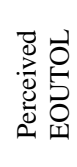 & 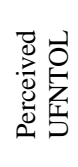 & 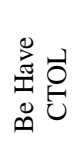 & 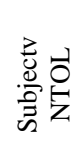 & 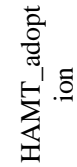 \\
\hline Attitude TOL & 1 & & & & & $.788^{* * *}$ \\
\hline Perceived EOUTOL & & 1 & & & & $.865^{* *}$ \\
\hline Perceived UFNTOL & & & 1 & & & $.730^{* *}$ \\
\hline Be Have CTOL & & & & 1 & & $.791^{* *}$ \\
\hline Subjectv NTOL & & & & & 1 & $.435^{* *}$ \\
\hline HAMT_adoption & & & & & & 1 \\
\hline
\end{tabular}

**. Correlation is significant at the 0.01 level (2-tailed).

The Table above shows the correlation matrix among construct dependent variable (DV) and the independent variables (IV), thus Attitude (AttitudeTOL), Perceived Ease of Use (PerceivedEOUTOL), Perceived Usefulness (PerceivedUFNTOL), Behaviour Control (BeHaveCTOL), Subjective Norms (SubjectvNTOL) and Adoption (HAMT_adoption). The results illustrates a strong uphill (positive) rapport between the dependent variable and the independent variables, with the exception of Subjective Norm (SubjectvNTOL) which shows a weak uphill relationship but still remain significant. There is a strong uphill relationship between Attitude (AttitudeTOL) $(r=.788 \mathrm{p}<0.01)$ Peceived Ease of Use $(r=.865 \mathrm{p}<0.01)$, Perceived Usefulness (PerceivedUFNTOL) ( $\mathrm{r}=.730$ $\mathrm{p}<0.01)$, Behaviour Control (BeHaveCTOL) $\quad(\mathrm{r}=.791$ $\mathrm{p}<0.01)$ and HAMT adoption, while Subjective Norms $(\mathrm{r}=.435 \mathrm{p}<0.01)$ indicate a weak correlation. However, Perceived Ease of Use was unique as it inversely allied to Adoption; Perceived Ease of Use (PerceivedEOUTOL) $(r=-.865 \mathrm{p}<0.01)$ which gave the highest degree of correlation among the Variables Used. The alternative hypothesis in this case, is accepted contrary to the null hypothesis $\mathrm{H} 1, \mathrm{H} 2$, $\mathrm{H} 3$, and $\mathrm{H} 4$.

\subsubsection{Regression Analysis}

Table 3 represents the summary of the regression test analysis for the independent variables; Subjective Norms (Subjectv NTOL), Attitude (Attitude TOL,) Perceived Usefulness (Perceived UFNTOL), Subjective Control (BeHave CTOL) Perceived Ease of Use (Perceived EOUTOL) and the dependent variable HAMT adoption. The model, in general, derived a correlation coefficient of $(r=.998)$ which indicates a strong linear relationship between measured variables which is HAMT adoption and the predictor variables; Subjective Norms (Subjectv NTOL), Attitude (Attitude TOL,) Perceived Usefulness (PerceivedUFNTOL), Subjective Control (BeHaveCTOL) Perceived Ease of Use (PerceivedEOUTOL). The coefficient of determination derived $\left(\mathrm{R}^{2}=.774\right)$ signifying nearly $77 \%$ of the total variability in the measured variable is explained for by the predictor variables. In other words Subjective Norms (Subjectv NTOL), Attitude (Attitude TOL,) Perceived Usefulness (Perceived UFNTOL), Subjective Control (BeHave CTOL) and Perceived Ease of Use (Perceived EOUTOL) describes nearly $77 \%$ of the volume of distinction in HAMT adoption. The calculated Adjusted R square derived 0.589 signifying that, around 59\% of the influences on HAMT adoption is described by the model, while $41 \%$ offers justification outside the model. This shows that $41 \%$ of causatives influencing HAMT adoption may be owed to other elements outside the model.

A linear regression analysis was carried out to test if Subjective Norms (Subjectv NTOL), Attitude (Attitude TOL,) Perceived Usefulness (Perceived UFNTOL), Subjective Control (BeHave CTOL) Perceived Ease of Use (Perceived EOUTOL) significantly predicted HAMT adoption. The results from the regression showed the five predictors explained almost $60 \%$ of the variance $\left(\mathrm{R}^{2}=.599, \mathrm{~F}(5,194)=\right.$ 58.068, $\mathrm{p}<.05$ ). It was found that Subjective Norms, Attitude, Perceived Usefulness, Subjective Control and Perceived Ease of Use significantly predicted HAMT adoption.

Table 3. Model Summary

\begin{tabular}{|c|c|c|c|c|c|c|c|}
\hline \multirow{2}{*}{ Model } & \multirow{2}{*}{$\mathrm{R}$} & \multirow{2}{*}{ R Square } & \multirow{2}{*}{ Adjusted R Square } & \multirow{2}{*}{ Std. Error of the Estimate } & \multicolumn{3}{|c|}{ Change Statistics } \\
\hline & & & & & R Square Change & F Change & Sig. F Change \\
\hline 1 & $.774^{\mathrm{a}}$ & 0.599 & 0.589 & 0.29102 & 0.599 & 58.068 & 0.000 \\
\hline
\end{tabular}

a. Predictors: (Constant), Subjectv NTOL, Attitude TOL, Perceived UFNTOL, Be Have CTOL, Perceived EOUTOL.

Table 4. ANOVA ${ }^{\mathrm{a}}$

\begin{tabular}{ccccccc}
\hline & Model & Sum of Squares & df & Mean Square & F & Sig. \\
\hline \multirow{2}{*}{1} & Regression & 24.590 & 5 & 4.918 & 58.068 \\
& Residual & 16.430 & 194 & 0.085 & $.000^{\mathrm{b}}$ \\
& Total & 41.020 & 199 & & \\
\end{tabular}

a. Dependent Variable: HAMT_adoption

b. Predictors: (Constant), Subjectv NTOL, Attitude TOL, Perceived UFNTOL, BeHave CTOL, Perceived EOUTOL 
Table 5. Coefficients ${ }^{\mathrm{a}}$

\begin{tabular}{clccccc}
\hline \multirow{2}{*}{ Model } & \multicolumn{2}{c}{ Unstandardized Coefficients } & Standardized Coefficients & t & Sig. \\
& (Constant) & 0.379 & 0.189 & & & \\
\hline \multirow{2}{*}{1} & AttitudeTOL & 0.185 & 0.067 & 0.218 & 2.000 & 0.047 \\
& PerceivedEOUTOL & 0.184 & 0.050 & 0.266 & 3.670 & 0.006 \\
& PerceivedUFNTOL & 0.149 & 0.040 & 0.226 & 3.718 & 0.000 \\
& BeHaveCTOL & 0.218 & 0.053 & 0.269 & 4.114 & 0.000 \\
& SubjectvNTOL & 0.133 & 0.034 & 0.202 & 3.968 & 0.000 \\
\hline
\end{tabular}

a. Dependent Variable: HAMT adoption.

Table above shows the outcome of coefficients of the various predictors of HAMT adoption. The model shows that, Subjective Norms (Subjectv NTOL), Attitude (Attitude TOL,) Perceived Usefulness (Perceived UFNTOL), Subjective Control (Be Have CTOL) Perceived Ease of Use (Perceived EOUTOL) are significant predictors of HAMT adoption, ( $\beta=0.185$ for Attitude TOL, .184 for Perceived EOUTOL, .149 for Perceived UFNTOL, .218 for BeHave CTOL and .133 for Subjectv NTOL, $\mathrm{t}=2.764$ (Attitude TOL), 3.670 (Perceived EOUTOL), 3.718 (Perceived UFNTOL) 4.114 for Be Have CTOL) and 3.968 for Subjective Norms (Subjectv NTOL), $\mathrm{p}=.000, \mathrm{R}^{2}=0.599$ ) therefore the null hypothesis is rejected in favour of the alternative.

Thus;

- H1: there is a significant correlation between Attitude and HAMT adoption.

- H2: Perceived Ease of Use significantly affect HAMT adoption.

- H3: Perceived Usefulness is inversely related to HAMT adoption.

- H4: there is exist a significant relationship between social Behavior Control and HAMT adoption

- H5: There is a significant relationship between Subjective Norms and HAMT adoption.

Furthermore, there is confirmation that the independent variables construct facilitated to predict the dependent variable $(\mathrm{p}<.05)$ indicating some descriptive control in the model.

\section{Discussion}

The results of the study fascinatingly demonstration the significant factors of HAMT adoption and the impact of each delineated element. The outcomes established that the majority of health workers will adopt HAMT base on their Perceived Usefulness, Perceived Ease of Use, Attitude, Subjective Norms, and Subjective Behaviour. The findings of this study is in consistency with other research works, such as Fathema, David, Margaret, [33] who concluded that, adoption of technology is dependent on the benefits or usefulness of such technology, the ease of using it and whenever modernized method is cogitated to be more beneficial than it old-style system of executing the same undertakings, the adoption of that technology is high. Adoption of innovative and technology system is therefore associated with perceived benefits to be derived from adopting such technology as stipulated by Moore \& Benbasat [34]. Consideration should also be given to pass experience of adopters of new technology as they may feel reluctant to adopt because pass experience could affect their attitude to adopt [35]. The work of Bala, Hillol Venkatesh, Viswanath also came with the same conclusion, that complex technology contribute to low adoption of technology at the work place and in this regard it is important for Organization to take proactive measures to adopt technology because if technology is easy to use the more likely that it will be accepted and adopted [36]. The study has shown that Subjective Norms, Attitude, Perceived Usefulness, Subjective Control and Perceived Ease of Use are significant predictors of HAMT adoption.

\section{Implications of the Study}

Technology adoption in the health sector is a matter of debate amid health professionals of contemporary health. Taking into Consideration the phenomenon that, the adoption rate of Hospital Management Technology is still fringe and marginalized, this research finds that Subjective Norms, Attitude, Perceived Usefulness, Subjective Control and Perceived Ease of Use are some of the salient factors influencing the adoption of Hospital Administration Management Technology. This paper in consistency with other research, help the researchers of this study to suggest, there is the need for Heads of Health centers and hospitals in Ghana and around the world to maximize time and technology by adopting Innovations that will enhance service delivery in the health sector, taking into consideration, the factors that may influence proper adoption and implementation.

\section{Conclusion}

The proliferation of Innovation and technology in the health sector has been seen as the driven swivel of smooth and proper health delivery tool. Nevertheless, the adoption of Hospital Administration Management Technology still remains very minor compared to the number of hospitals and the size of the Health Sector.

Considering the extensive spread of Innovative technologies in the Health sectors around the world, it does not echo on the Ghanaian health workers preference for adoption for advance health delivery, it is therefore essential to study what influential preferences stimulate the adoption of Technology for health service delivery systems in the Ghanaian Health Sector. 


\section{References}

[1] V. K. Omachonu, "Innovation in Healthcare Delivery Systems: A Conceptual Framework,” Innov. J. Public Sect. Innov. J., vol. 15, no. 1, pp. 1-21, 2010.

[2] M. G. Aboelmaged and T. R. Gebba, "Mobile Banking Adoption: An Examination of Technology Acceptance Model and Theory of Planned Behavior,” Int. J. Bus. Res. Dev., vol. 2, no. 1, pp. 35-50, 2013.

[3] C. M. Christenson, A. D, and E. A. Roth, "Seeing What's Next: Using the Theories of Innovation to Predict Industry Change," Harvard Bus. Sch. Press, vol. 293, 2004.

[4] “Electronic Health Records: A Global Perspective,” 2010.

[5] R. Borzekowski, "Health Care Finance and the Early Adoption of Hospital Information Systems.,” SSRN eLibrary, 2002.

[6] N. A. OGBOBE, "Automated Hospital Management System," University of Nigeria, Nsukka, Nigeria, 2011.

[7] l K. Ö. Gönü, "Resource Based View , Core Competence and Innovation: A Research on Turkish Manufacturing Industry,” Sci. Res. J., vol. I, no. Iii, pp. 9-17, 2013.

[8] E. Poon, J. Ashish, C. Melissa, H. Melissa, and N. Rushik, Fernandopulle Blackford, Middleton Joseph, “Assessing the level of healthcare information technology adoption in the United State.," BMC Med. Inform. Decis. Mak., vol. 6, 2006.

[9] A. K. Jha et al., "Use of Electronic Health Records in U.S. Hospitals,” N. Engl. J. Med., vol. 16, p. 1627-1639., 2009.

[10] "Overcoming Challenges to Health IT Adoption in Small, Rural Hospitals,” Altar. Inst., no. October, 2011.

[11] M. . West and J. . Farr, "The Social Psychology of Innovation in Groups Innovation and Creativity at Work,” 1990.

[12] C. . Armitage and M. Conner, "Efficacy of the theory of planned behavior 40 No. 3, pp. 471-99,” Br. J. Soc. Psychol., vol. 40, no. 3, pp. 470-500, 2001.

[13] V. Venkatesh, "Determinants of perceived ease of use: integrating control, intrinsic motivation, and emotion into the technology acceptance model.," Inf. Syst. Res., vol. 11, no. 4, pp. 341-66, 2000.

[14] M. Venkatesh, G. Morris, and F. D. Davis, "User acceptance of information technology toward a unified view," MIS Quaterly, vol. 27, no. 3, 2003.

[15] C. Chen, Y. Fan, and C. Farn, "Predicting electronic toll collection service adoption: an integration of the technology acceptance model and the theory of planned behavior,” Transp. Res., vol. 15, p. 300, 2007.

[16] S. Taylor and P. A. Todd, ““"Understanding information technology usage: a test of competing models," Inf. Syst. Res., vol. 6, no. 2, pp. 143-175, 1995.

[17] I. Fishbein and J. Ajzen, "Beliefs, Attitude, Intention and Behaviour: An Introduction to Theory and Research,” Addison-Wesley, 1975.

[18] [F. Davis, R. Bagozzi, and P. Warshaw, "User acceptance of computer technology: a comparison of two theoretical models," Management science, vol. 35, no. 8. pp. 982-1003, 1989.

[19] F.. Davis, "Perceived usefulness, perceived ease of use, and user acceptance on information technology,” MIS Q., vol. 13, no. 3, pp. 318-340, 1989.

[20] X. Tong, "A cross-national investigation of an extended technology acceptance model in the online shopping context," Int. J. Retail Distrib. Manag., vol. 38, 2010.

[21] V. Ratten, “A cross-cultural comparison of online behavioral advertising knowledge, online privacy concerns and social networking using the technology acceptance model and social cognitive theory,” J. Sci. Technol. Policy Manag. 6 Forthcom., 2015.

[22] T. Gao, A. . Rohm, F. Sultan, and S. Huang, “Antecedents of consumer attitudes toward mobile marketing: a comparative study of youth markets in the United States and China,” hunderbird Int. Bus. Rev., vol. 54, pp. 210-26, 2012.

[23] K. Hu and S. O. Brien, “Applying TAM ( Technology Acceptance Model) to testing MT acceptance Our research Limitations of TAM,” 2017.

[24] F. David, "Perceived usefulness, perceived ease of use, and user acceptance of information technology,” MIS Quaterly, vol. 13, 1989.

[25] L. Li, “A Critical Review of Technology Acceptance Literature.”

[26] K. Mathieson, "Predicting User Intentions: Comparing the Technology Acceptance Model with the Theory of Planned Behavior,” Inf. Syst. Res., vol. 2, no. 3, 1991.

[27] J. Hartwick and H. Barki, "'Explaining the Role of User Participation in Information System Use,’ (40:4), 1994, pp. 440-465.,” Manage. Sci., vol. 40, no. 4, pp. 440-466, 1994.

[28] V. Venkatesh and F. D. Davis, “A theoretical extension of the technology acceptance model: four longitudinal field studies. Manage. Sci. 46 (2), 186-204.,” 2000.

[29] C.-H. S. Lin and C.-F. Chen, “Application of Theory of Planned Behavior on the Study of Workplace Dishonesty,” 2010 Int. Conf. Econ. Bus. Manag., vol. 2, pp. 66-69, 2011.

[30] C. J. Armitage and M. Conner, "Efficacy of the theory of planned behaviour: A meta-analytic review,” Br. J. Soc. Psychol., vol. 40, pp. 470-500, 2001.

[31] J. R. Smith, D. J. Terry, A. S. Manstead, W. R. Louis, D. Kotterman, and J. Wolfs, "The attitude-behavior relationship in consumer conduct: The role of norms, past behaviors, and self-identity.,” J. Soc. Psychol., vol. 148, no. 3, pp. 311-335, 2008.

[32] C. N. and A. Earl, "The Wiley Encyclopedia of Health Psychology,” Wiley Encycl. Heal. Psychol., 2015.

[33] N. Fathema, S. David, and R. Margaret, "Impact of Social Media Usage Factors on Green Choice Behavior Based on Technology Acceptance Model,” J. Adv. Manag. Sci., vol. 11, no. 2, pp. 92-97, 2016.

[34] G. Moore and I. Benbasat, "Development of an instrument to measure the perceptions of adopting an information technology innovation.," Inf. Syst. Res., vol. 2, no. 3, pp. 192-222, 1991.

[35] M. Ghazizadeh, J. D. Lee, and L. N. Boyle, "Extending the Technology Acceptance Model to assess automation," Cogn. Technol. Work, vol. 14, no. 1, pp. 39-49, 2012.

[36] H. Bala and V. Venkatesh, "Technology acceptance model 3 and a research agenda on interventions,” Decis. Sci., vol. 39, no. 2, pp. 273-315, 2008. 